\section{$\underset{\substack{\text { hommes } \\ \text { \& migrations }}}{ }$}

\section{Hommes \& migrations}

Revue française de référence sur les dynamiques

migratoires

\section{$1284 \mid 2010$}

Migrations et environnement

\title{
Soul Kitchen
}

Film germano-turc de Fatih Akin

\section{André Videau}

\section{Q OpenEdition \\ 1 Journals}

\section{Édition électronique}

URL : http://journals.openedition.org/hommesmigrations/1273

DOI : 10.4000/hommesmigrations. 1273

ISSN : 2262-3353

\section{Éditeur}

Musée national de l'histoire de l'immigration

\section{Édition imprimée}

Date de publication : 1 mars 2010

Pagination : 179

ISSN : 1142-852X

\section{Référence électronique}

André Videau, « Soul Kitchen », Hommes \& migrations [En ligne], 1284 | 2010, mis en ligne le 29 mai

2013, consulté le 23 septembre 2020. URL : http://journals.openedition.org/hommesmigrations/1273

; DOI : https://doi.org/10.4000/hommesmigrations.1273

Ce document a été généré automatiquement le 23 septembre 2020.

Tous droits réservés 


\section{Soul Kitchen}

Film germano-turc de Fatih Akin

André Videau 
1 À la sortie de Soul Kitchen, son quatrième film (après Head on, 2004; Crossing the bridge, 2005 ; De l'autre côté, 2007), le jeune réalisateur Fatih Akin, né à Hambourg il y a trentesept ans, a déclaré avec un sérieux imperturbable qu'il avait voulu faire une pause. À la vue du résultat vibrionnant qui, de sons endiablés en aventures burlesques, ne laisse pas un instant de répit, ni aux personnages, ni aux spectateurs, il aurait été plus juste d'annoncer un avis de tempête.Jugez plutôt : sur les docks périphériques de Hambourg, la cosmopolite, Zinos (Adam Bousdoukos, transfuge grec et acteur d'élection du réalisateur) tient cantine à l'enseigne de "Soul Kitchen". Fleuron de la culture alternative, le lieu s'adapte aux perpétuelles mutations du quartier. De la gargote pour paumés à la grande bouffe gastronomique et branchée. Tout cela ne va pas sans remueménage et tohu-bohu, d'autant qu'il faut aussi faire place aux répètes d'un tonitruant groupe de soul music, rock et autres, en matinée et finir la soirée en boîte.

Pour l'heure, la vogue est à un cuistot génial et caractériel (le fantasque Birol Ünel). La clientèle et les recettes affluent. Les emmerdements aussi. C'est d'abord le frère Ilias (Moritz Bleibtreu) malfrat tout juste sorti de prison et en liberté conditionnelle, que l'esprit de famille condamne à secourir. C'est ensuite la copine Nadine, irrésistible de blondeur (Pheline Roggan) qui veut faire un breack à Shangaï et pousse Zinos à tout laisser tomber pour la suivre. C'est encore la douleur insoutenable d'une hernie discale qui ne lui laisse le choix qu'entre l'opération ou la paralysie, les recours à une kiné trop douce et à un rebouteux trop brutal s'étant avérés inefficaces. Passons sur les frasques de la serveuse (la piquante brune Anna Bedeker), du vieux poivrot qui vit aux crochets de la communauté, l'inspection du service hygiénique, le contrôle fiscal, la distribution inopinée d'aphrodisiaques et la partouze qui s'ensuivit, l'influence d'un bouton de manchette sur le cours d'une enchère... C'est beaucoup pour un seul homme mais n'hésitez pas, l'adresse est bonne, la bouffe mijotée à point, le film délectable.

3 Un mot du réalisateur en réponse à la fatidique question des origines : "je ne viens ni de Turquie, ni d'Allemagne, mais de la planète cinéma". C'est bon! 